\title{
Metal Hydrides Based High Energy Density Thermal Battery
}

Zhigang Zak Fang ${ }^{\mathrm{a}, *}$, Chengshang Zhou ${ }^{\mathrm{a}}$, Peng Fan ${ }^{\mathrm{a}}$, Kent S. Udell ${ }^{\mathrm{b}}$, Robert C. Bowman ${ }^{\mathrm{a}}$, John J. Vajo $^{c}$, Justin J. Purewal ${ }^{c}$, Bidzina Kekelia ${ }^{b}$

a Department of Metallurgical Engineering, The University of Utah, 135 South 1460 East, Room 412, Salt Lake City, Utah 84112-0114

b Department of Metallurgical Engineering, The University of Utah, 50 S. Central Campus Dr., Room 2110, Salt Lake City, Utah 84112-0114

c HRL Laboratories, LLC, 3011 Malibu Canyon Road, Malibu, California 90265

*Corresponding author: zak.fang@utah.edu, +1 801-581-8128

\begin{abstract}
A concept of thermal battery based on advanced metal hydrides was studied for heating and cooling of cabins in electric vehicles. The system utilized a pair of thermodynamically matched metal hydrides as energy storage media. The pair of hydrides that was identified and developed was: (1) catalyzed $\mathrm{MgH}_{2}$ as the high temperature hydride material, due to its high energy density and enhanced kinetics; and (2) $\mathrm{TiV}_{0.62} \mathrm{Mn}_{1.5}$ alloy as the matching low temperature hydride. Further, a proof-of-concept prototype was built and tested, demonstrating the potential of the system as HVAC for transportation vehicles.
\end{abstract}

Keywords: Metal hydride; thermal energy storage; energy density; thermal battery 


\section{Introduction}

Thermal energy storage (TES) is one of the most promising approaches for harnessing and utilizing thermal energies, such as solar energy and industrial waste heat. TES is generally classified by different forms of storing heat such as: sensible heat, latent heat, and chemical energy. [1] Of all these forms, the use of thermo-chemical energy has received growing interest due to its intrinsic high energy-density. [2] In particular, a metal hydride based TES system is very appealing due to the fact that many metals and alloys can combine with hydrogen to form metal hydrides under favorable temperature and hydrogen pressure conditions. The basic idea of using metal hydrides for thermal engineering applications was originated in the 1970's, when Libowitz [3,4] suggested that the hydrogenation and dehydrogenation reactions could be used for TES. It was recognized that the substantial heats of reaction associated with hydrogenation (exothermic) and dehydrogenation (endothermic) reactions can be utilized for various practical purposes such as thermal storage, heat pumps, and heating and cooling systems. [5] There is considerable renewed interest in the use of metal hydrides for TES, including reports by Ono, [6] Yonezu et al, [7] and a recent review by Muthukumar et al. [8]

A common thread of the past research reports on metal hydride based thermal applications has been that most, if not all, utilize intermetallic $\mathrm{AB}_{5}$ and/or $\mathrm{AB}_{2}$ alloys as hydride materials, [8] which offer the advantages of excellent kinetic behavior and cyclic stability. However intermetallic metal hydrides suffer drawbacks including: (1) high cost of the misch metals; and (2) low hydrogen capacity (typically less than $1.8 \mathrm{wt} \%$ hydrogen capacity), and hence low energy density, particularly low gravimetric energy density. The cost and weight of the intermetallic alloys are considered a major limitation, impeding their application in electric vehicles. 
Bogdanovic et al. [9-11] suggested that Mg-based hydride systems could be used for TES because these systems cover a wide temperature range from $250{ }^{\circ} \mathrm{C}$ to $550{ }^{\circ} \mathrm{C}$ and have high thermal energy density, up to $2257 \mathrm{~kJ} / \mathrm{kg}$. However, pure $\mathrm{MgH}_{2}$, is known to have poor kinetic rates for both the dehydrogenation and hydrogenation reactions. Fortunately, recent progresses on hydrogen storage materials have shown that several nano-catalyzed $\mathrm{Mg}$ materials [12-17] are capable of absorbing a significant amount of hydrogen at room temperature. These findings have paved the way to practical application of Mg-based hydrides.

In this paper, we introduce the concept of a high-energy-density thermal battery based on exploiting the differences between hydrogen equilibrium pressures of $\mathrm{Mg}$-based hydrides and intermetallic alloys (from $\mathrm{AB}_{2}, \mathrm{AB}_{5}$ or $\mathrm{BCC}$ families) at relevant temperatures. The present research focused on a specified onboard application to develop a novel heating, ventilation, and air conditioning (HVAC) system for electric vehicles (EV). However, the methodology of the thermal battery could be extended to a much broader range of applications, including other transportation vehicles such as long haul trucks, stationary HVAC, solar thermal energy storage systems, and waste heat recovery and storage systems.

\section{Concept}

As shown in Figure 1, the thermal battery utilizes a thermodynamically-coupled pair of metal hydrides: one of which is designated as the high temperature (HT) hydride because it will provide heat. The HT hydride has a low equilibrium pressure and can release heat (exothermic) when it absorbs hydrogen; and it decomposes only at moderately higher temperatures. The other hydride is designated as the low temperature (LT) hydride because it will provide cooling (endothermic) when it dehydrogenates. The LT hydride has higher equilibrium pressure than the HT hydride has, and when releasing hydrogen the LT hydride absorbs heat from its local environment. 
Cooling \& Heating (Discharge mode): At the beginning of a cycle, the LT hydride is contained in a low temperature hydride bed (LT-HB) and is in a hydrogenated state, while the HT hydride material is placed in a high temperature hydride bed (HT-HB) and is in dehydrogenated state (alloy). When the valve between the two beds is open, hydrogen will flow from the LT-HB to the HT-HB (see Fig. 1, left), because the equilibrium $\mathrm{H}_{2}$ pressure of the LT hydride is higher than that of the HT hydride. The endothermic dehydrogenation in the LT-HB and exothermic hydrogenation in the HT-HB occur simultaneously.

Recharging mode: External heat (could be from electric heater or other thermal energy sources) will be used to heat the HT-HB causing it to dehydrogenate, as shown in Fig. 1 (Right). The $\mathrm{H}_{2}$ released from the HT-HB will flow back to the LT-HB to rehydrogenate, i.e. recharge the LT hydride material in the LTHB. During recharging, the external energy (e.g. from an electric outlet) is in essence stored as thermal chemical energy in the hydride that will be release for service during discharging. The system is hence termed a "battery", a term that implies the storage of energy that can be used when and where it is needed.

In reality, using metal hydrides for heating/cooling of a vehicle faces many material and engineering challenges. The metal hydrides selected for the system must meet the following requirements:

- Two hydrides must have complimentary thermodynamic properties that would enable the discharging and charging of the system at specified desired temperatures for a given application.

- The hydride must have fast kinetic rates during dehydrogenation as well as hydrogenation which is essential to provide heating or cooling when and where it is needed.

- The system must have good cyclic stability and durability. 
- The hydride must have both gravimetric and volumetric high energy density to be viable to compete with other energy sources such as electric battery.

\section{Selection of the Hydride Materials}

As mentioned above, the selection of the two hydride materials must have complimentary thermodynamic properties to enable discharging and charging of the thermal battery in desired temperature ranges. Specifically, for discharging of the thermal battery, the equilibrium pressure of the LT hydride must be high enough at the ambient temperature (e.g. -10 to $30{ }^{\circ} \mathrm{C}$ ) so that the HT hydride metal can be hydrogenated at temperatures at or above the ambient temperature. For charging of the thermal battery, the equilibrium pressure of the HT hydride at an elevated temperature (e.g. 200 to $350{ }^{\circ} \mathrm{C}$ ) must be high enough to hydrogenate the LT hydride metal at ambient temperature. To identify a candidate pair of hydride materials, a survey of a large number of potential hydride materials was conducted based on thermodynamics properties.

HT Hydride: Figure 2 is the van't Hoff plots of selected hydrides. The HT hydrides are on the left side of the diagram, while the LT hydrides are on the right. Figure 2 shows that there are few options for the HT hydride considering that the temperature for recharging of the thermal battery should not be more than $400{ }^{\circ} \mathrm{C}$ for practical reasons. Catalyzed nano-sized $\mathrm{MgH}_{2}$ was thus selected as the candidate HT hydride material. Because of a high usable hydrogen capacity, up to $7.0 \mathrm{wt} . \%$, and a high reaction enthalpy of 75 $\mathrm{kJ} / \mathrm{mol} \mathrm{H}_{2}, \mathrm{MgH}_{2}$ has a high gravimetric energy density. Relevant properties of $\mathrm{MgH}_{2}$ and other comparable HT hydride candidates are summarized in Table 1. It can be seen that the gravimetric energy density and volumetric energy density of $\mathrm{Mg} / \mathrm{MgH}_{2}$ are $2831 \mathrm{~kJ} / \mathrm{kg}$ and $4020 \mathrm{~kJ} / \mathrm{L}$, respectively. 
LT Hydride: Once the HT hydride was determined, candidates for the LT hydride were selected from the shaded square in Fig. 2. First, to hydrogenate magnesium during the discharging mode, it was expected that at least 1-bar hydrogen pressure would be needed from the LT hydride. Second, to recharge the system in relatively warm climate conditions (e.g. summer in the southern US), the equilibrium pressure of the LT hydride at $40{ }^{\circ} \mathrm{C}$ must be low enough so that hydrogen can flow back from the heated HT hydride and hydrogenate the LT bed. On the basis of the above criteria, the shaded area in Fig. 2 shows the range of van't Hoff plots for suitable LT hydride candidates. Several LT hydride candidates were identified, including: 75V-5Ti-Cr, $\mathrm{TiV}_{0.62} \mathrm{Mn}_{1.5}, \quad\left(\mathrm{~V}_{0.9} \mathrm{Ti}_{0.1}\right)_{0.95} \mathrm{Fe}_{0.05}, \mathrm{TiMn}_{2}$ HYDRALLOY, TiMn ${ }_{1.5}$ HYDMAC8, and $\mathrm{LaNi}_{5}$. Relevant properties of those hydrides are provided in Table 1.

The LT hydrides which had van't Hoff plots crossing the shaded area in Fig. 2 were considered as candidates to pair with $\mathrm{MgH}_{2}$, but the use of these LT hydrides would be expected to result in significantly different impacts on the performance of a thermal battery system. For example, hydrides with van't Hoff lines on the right side in Fig. 2, i.e. TiMn 2 HYDRALLOY, TiMn 1.5 HYDMAC8, can provide relatively higher pressures to hydrogenate $\mathrm{Mg}$, which would lead to enhanced cooling and heating system performance due to the large difference between the equilibrium pressures of the HT-HB and the LT-HB. However, using the high-pressure LT hydrides may cause difficulties during recharging of the system because higher temperatures would be required to heat the HT-HB to provide sufficiently high pressure for recharging the LT-HB. The over-heating of $\mathrm{MgH}_{2}$ should, however, be avoided due to the potential risk of its degradation at elevated temperatures. [6] In comparison, hydrides such as $\left(\mathrm{V}_{0.9} \mathrm{Ti}_{0.1}\right)_{0.95} \mathrm{Fe}_{0.05}, \mathrm{LaNi}_{5}$, and $\mathrm{LaNi}_{4.7} \mathrm{Sn}_{0.3}$, can be easily rehydrogenated under relatively low pressure. The problem of using these lower pressure LT hydrides lies in the potential of decreasing system performance, since the kinetics of hydrogenating Mg would be slower at lower pressures. Considering the facts that are discussed above, $\mathrm{TiV}_{0.62} \mathrm{Mn}_{1.5}$ alloy was selected as the LT hydride for this study. The thermodynamic properties of $\mathrm{TiV}_{0.62} \mathrm{Mn}_{1.5}$ are well balanced for both discharging and recharging. 
Once the hydrides were selected, the theoretical COP (Coefficient of Performance) can be calculated as follow:

COP $P_{\text {cooling }}=\frac{\Delta H_{l}}{\Delta H_{h}}=\frac{28.6}{74.5}=0.384$

$C O P_{\text {heating }}=\frac{\Delta H_{h}}{\Delta H_{h}}=1$

Where $\Delta \mathrm{H}_{1}$ and $\Delta \mathrm{H}_{\mathrm{h}}$ were the reaction enthalpies of LT hydride $\left(\mathrm{TiV}_{0.62} \mathrm{Mn}_{1.5}\right)$ and HT hydride $\left(\mathrm{MgH}_{2}\right)$, respectively.

\section{Experimental}

\subsection{Materials Preparation}

Catalyzed $\mathrm{MgH}_{2}$ was prepared by co-milling $\mathrm{MgH}_{2}$ (Sigma-Aldrich) with $\mathrm{TiMn}_{2}$ (Sigma-Aldrich) using a high energy planetary ball mill. Details of the milling method and properties of the as-milled product can be found in our previous publication. [16] After milling, $50 \mathrm{~g}$ of $\mathrm{TiMn}_{2}$ catalyzed $\mathrm{MgH}_{2}$ was mixed with 5 wt.\% expanded graphite (ENG). Then, samples of the HT hydride materials, with and without graphite, were loaded into two HT-HBs. For the LT-HB, 190 grams of as-received $\operatorname{TiMn}_{1.5} \mathrm{~V}_{0.62}$ alloy (GfE, Hydralloy C) were activated in an autoclave, then loaded into the thermal battery apparatus. All material handling was carried out in a glove-box filled with circulating purified argon (99.999\%), which contains less than $1 \mathrm{ppm}$ water vapor and oxygen.

\subsection{Prototype Design}


A laboratory demonstration prototype was designed and fabricated to test candidate hydride materials for thermal batteries. As shown in Fig. 3(a), two HT-HBs were coupled with one LT-HB. A mass flow meter (Model: GFM 37 AALBORG Inc., Accuracy: $\pm 1.5 \%$ of full scale, Range: $0-20 \mathrm{~L} / \mathrm{min}$ ) and pressure gauges (PGI series, Swagelok) were incorporated to monitor hydrogen flow rate and hydrogen pressure, respectively, during operation. Figure 3(b) illustrates the construction of the hydride bed. K-type thermocouples were used to measure surface temperatures on the HT-HBs and the LT-HB.

\section{Results and Discussion}

\subsection{Hydride materials}

For the purpose of demonstrating the concept, the present work focused on verifying and testing the functionality of the system using the selected hydride materials. Extensive research efforts, including optimization of the hydride materials, have been reported elsewhere. [12,16,19] Initially, in order to verify thermodynamic compatibility of the two hydride candidate materials, hydrogen equilibrium pressures of $\mathrm{MgH}_{2}$ and TiMnV were characterized using a Sievert-type apparatus (PCT-Pro 2000). As

shown in Fig. 4, the results indicated that when $\mathrm{MgH}_{2}$ was heated to $390{ }^{\circ} \mathrm{C}, 15$ bar hydrogen pressure could be generated, which is sufficient to hydrogenate TiMnV alloy at room temperature. During discharge, decomposition of the TiMnV hydride at room temperature was able to provide 8 to 10 bar pressure, and the equilibrium pressure for hydriding $\mathrm{Mg}$ is fairly low at low temperature (e.g. the equilibrium pressure at $210{ }^{\circ} \mathrm{C}$ is 0.08 bar).

The performance of the thermal battery, as an HVAC system, requires that a sufficient amount of heat or cooling must be provided within a short period of time. This is largely dependent on the kinetics of the hydrides, i.e. hydriding rate of catalyzed $\mathrm{Mg}$ and dehydriding rate of TiMnV hydride at low temperature. To evaluate the system for functionality in this regard, isothermal evaluations of the kinetics of $\mathrm{TiMn}_{2}$ 
catalyzed $\mathrm{MgH}_{2}$ and TiMnV hydride were conducted, and results are given in Fig. 5a, and 5b, respectively. These results show that $\mathrm{TiMn}_{2}$ catalyzed $\mathrm{MgH}_{2}$ was able to uptake $2.5 \mathrm{wt} \%$ hydrogen under 1-bar pressure at $22{ }^{\circ} \mathrm{C}$. The effect of temperature on the hydrogenation kinetics was also found to be significant. When temperature was increased from $22{ }^{\circ} \mathrm{C}$ to $52{ }^{\circ} \mathrm{C}$, a dramatic improvement of the kinetics was observed. A $\mathrm{H}_{2}$ charge test of the HT hydride $\left(\mathrm{TiMn}_{2}\right.$ catalyzed $\left.\mathrm{MgH}_{2}\right)$ bed was further carried out by introducing 10.5-bar $\mathrm{H}_{2}$ into the dehydrided HT bed, as shown in Fig. 5c. A pronounced temperature spike (from room temperature to $360{ }^{\circ} \mathrm{C}$ ) of the HT bed was observed during the feeding of the pressurized hydrogen. This temperature spike is due to the hydrogenation of $\mathrm{Mg}$ being a highly exothermic reaction and is normal for this material. The increase temperature, in turn, boosted the rate of hydrogenation, which corresponds to the observed kinetic measurements of the material, (Fig. 5a). The LT hydride, TiMnV, was able to fully dehydrogenate within 1 min at $25^{\circ} \mathrm{C}$ (Fig. 5b). Further, the quick dehydriding behavior of TiMnV allowed the LT bed to cool to $-5{ }^{\circ} \mathrm{C}$ from room temperature during the LT bed discharge test.

\subsection{Prototype test}

In order to better understand the effects of thermal conductivity of the hydride materials, one HT-HB was loaded with catalyzed $\mathrm{MgH}_{2}$ and the other was loaded with a mixture of catalyzed $\mathrm{MgH}_{2}$ with 5 wt.\% ENG. Before discharging, the HT-HBs were heated to and held at $270{ }^{\circ} \mathrm{C}$ for 3 hrs to fully dehydrogenate the HT hydride, and the LT hydride was hydrogenated using 20 bar pressure. After the dehydrogenation of the HT-HBs and the hydrogenation of the LT-HB, all the hydride beds were allowed to cool to room temperature. The valve between the HT-HB and the LT-HB was then opened to discharge the thermal battery. The temperature profiles of the hydride beds during discharging are shown in Fig. 6a, and the flow rate of hydrogen and the pressure of the system are plotted in Fig. 6b. First, it can be seen that the HT-HB\#1 (without addition of graphite) heated to $228{ }^{\circ} \mathrm{C}$ within 5 minutes. In contrast, the HT-HB\#2 (with addition of graphite) heated at a much slower rate; requiring 40 minutes to reach its maximum 
temperature of $96{ }^{\circ} \mathrm{C}$. Second, the LT-HB cooled to $-12{ }^{\circ} \mathrm{C}$ within the same time period. Third, once the valve was opened, the pressure of the system quickly decreased from 12.5 bar to below 1 bar. Corresponding to the pressure drop, a spike of hydrogen flow was observed within 3 minutes, indicating the fastest kinetic rates for reactions in both the HT-HB\#1 and the LT-HB.

An interesting observation during the discharging was the quick thermal response of the HT-HB\#1 (HT hydride without graphite) in contrast to a slow temperature build-up of the HT-HB\#2. Considering all the data including the temperature profiles, the pressure, and the flow rate, it is believed that the reaction rate of the material in the HT-HB \#1 was significantly higher than the material in HT-HB\#2. It should be pointed out that in earlier work, the kinetic studies of the two HT hydride materials (catalyzed $\mathrm{MgH}_{2}$ with and without addition of ENG) did not show an obvious kinetic difference. [20] This indicates that the difference between the temperature responses of the two HT beds was probably related to differences in the thermal conductivity of the two HT hydride materials. For the materials without the graphite thermal conductivity enhancer (HT-HB\#1), the rise in temperature occurred more quickly. As a result the material with higher thermal conductivity in HT-HB\#2 would eventually experience a temperature spike. Therefore, it is clear as expected that the thermal conductivity of the material and the hydride bed as a whole play an important role in the self-heating behavior of the hydride bed and the performance of the system.

Note that there was a pressure rise after the initial absorption (after discharge for $10 \mathrm{~min}$ ). This is directly correlated to the increase of temperature of the LT bed, which provides high hydrogen pressure. However, the pressure and temperature changes of the LT bed depends also on the rate of absorption of the HT beds. Therefore the pressure rise is likely due to the kinetic limitation of HT-HB\#2 and the completion of the reaction in $\mathrm{HT}-\mathrm{HB} \# 1$. When the kinetic rate of absorption of $\mathrm{HT}-\mathrm{HB} \# 2$ improved gradually (after $30 \mathrm{~min}$ in Fig. 6b), the hydrogen pressure of the system started to decrease again. 
Further, cooling and heating performance of the system can be determined by the measurement of hydrogen flow between LT bed and HT bed. The wattages of heating and cooling power of the thermal battery system can be obtained by the following equations:

$W_{c}=\frac{v_{H_{2}}}{V_{m}} \times \Delta H_{l}$

$W_{h}=\frac{v_{H_{2}}}{V_{m}} \times \Delta H_{h}$

Where $\mathrm{v}_{\mathrm{H} 2}$ is the flow rate of hydrogen, and $\mathrm{V}_{\mathrm{m}}$ is molar volume of hydrogen. Figure $6(\mathrm{c})$ plots the wattage of heating and cooling during the discharge. By integrating the wattage-time profile, the total cooling and heating energy are therefore estimated as $13.6 \mathrm{Whr}$ and $35.4 \mathrm{Whr}$, respectively.

Finally, it should be noted that cyclic stability of this thermal battery system is not reported in this work. However, cycle stability is one of the most critical performance characteristics of a thermal battery. It is part of the ongoing research of the present authors. The cycle stability of the system can in part be inferred by the stability of the hydrides that are used. It has been reported that TiMnV alloy is stable during $\mathrm{H}_{2}$ cycles. Mg-based hydride is considered to be cyclically stable hydrogen storage material in a temperature range of $200-400{ }^{\circ} \mathrm{C}$. For example, Reiser et al. [10] reported that Ni-doped $\mathrm{MgH}_{2}$ showed cyclic stability in the temperature range of $230-370{ }^{\circ} \mathrm{C}$, and they also suggested the material should avoid exposure to temperature over $420{ }^{\circ} \mathrm{C}$. However, research focusing on stability of low temperature kinetics of catalyzed Mg system is absent, which is also part of ongoing research and will be reported in the near future.

\section{Summary}

In this work, the concept of a thermal battery based on advanced metal hydrides was introduced. A laboratory prototype was designed, fabricated, and tested. The results successfully demonstrate the feasibility of the thermal battery using advanced metal hydrides including the high temperature hydride, 
$\mathrm{MgH}$, and the low temperature hydride, TiMnV, as a working pair with matching thermodynamic properties. The performance of the concept-demonstration-unit showed both high heating/cooling power and high energy densities.

\section{Acknowledgement}

This research was supported by the U.S. Department of Energy (DOE) under contract number DEAR0000173.

\section{References}

[1] B. Zalba, J. M. Marín, L. F. Cabeza, H. Mehling, Appl. Therm. Eng. 23(2003) 251.

[2] D. N. Harries, M. Paskevicius, D. A. Sheppard, T. E. C. Price, C. E. Buckley, Proc. IEEE 100(2012) 539.

[3] G. Libowitz, In 9th Intersociety Energy Conversion Engineering Conference, San Francisco, 1974, Proceedings. New York, American Society of Mechanical Engineers, 1974322.

[4] G. Libowitz, Z. Blank, In 11th Intersociety Energy Conversion Engineering Conference, 1(1976), 673.

[5] D. Gruen, M. Mendelsohn, I. Sheft, G. Lamich, In Hydrogen Energy System, Proc. $2^{\text {nd }}$ World Hydrogen Energy Conf. Zurich, vol.4. Pergamon Press 1979. 1931.

[6] S. Ono, M. Yamaguchi, T. Ohta, In Solar-Hydrogen Energy Systems. Oxford and New York, Pergamon Press 1979. 193.

[7] I. Yonezu, K. Nasako, N. Honda, T. Sakai J. Less-Common Met. 89(1983) 351.

[8] P. Muthukumar, M. Groll, Int. J. Hydrogen Energy, 35(2010) 8816.

[9] B. Bogdanović, A. Ritter, B. Spliethoff, Angew. Chem. Int. Ed. Engl. 29(1990) 223.

[10] A. Reiser, B. Bogdanović, K. Schlichte, Int. J. Hydrogen Energy 25(2000) 425.

[11] M. Felderhoff, B. Bogdanović, Int. J. Mol. Sci. 10(2009), 325. 
[12] C. Zhou, Z. Z. Fang, J. Lu, X. Zhang, J. Am. Chem. Soc. 135(2013), 10982.

[13] J. Lu, Y. J. Choi, Z. Z. Fang, H. Y. Sohn, E. Rönnebro, J. Am. Chem. Soc. 131(2009) 15843.

[14] G. Liang, J. Huot, S. Boily, A. Van Neste, R. Schulz, J. Alloy. Compd. 292(1999), 247.

[15] J. Lu, Y. J. Choi, Z. Z. Fang, H. Y. Sohn, E. Rönnebro, J. Am. Chem. Soc. 132(2010), 6616.

[16] C. Zhou, Z. Z. Fang, C. Ren, J. Li, J. Lu, J. Phys. Chem. C 117(2013) 12973.

[17] N. Hanada, T. Ichikawa, H. Fujii, J. Alloy. Compd. 446-447(2007) 67.

[18] G. Sandrock, G. Thomas, Appl. Phys. A 72(2001) 153.

[19] C. Zhou, Z. Z. Fang, J. Lu, X. Luo, C. Ren, P. Fan, Y. Ren, X. Zhang, J. Phys. Chem. C 118(2014) 11526.

[20] J. Li, P. Fan, Z. Z. Fang, C. Zhou, Int. J. Hydrogen Energy 39(2014) 7373. 
Table 1. Properties of hydride candidates.

\begin{tabular}{|c|c|c|c|c|c|c|c|c|}
\hline & \multirow[t]{2}{*}{ Materials } & \multirow{2}{*}{$\begin{array}{l}\text { H capacity, } \\
\text { wt. } \%\end{array}$} & \multirow{2}{*}{$\begin{array}{l}\Delta \mathrm{H}, \\
\mathrm{kJ} / \mathrm{mol} \mathrm{H}_{2}\end{array}$} & \multirow{2}{*}{$\begin{array}{l}\text { Density, } \\
\mathrm{kg} / \mathrm{L}\end{array}$} & \multirow{2}{*}{$\begin{array}{l}\mathrm{T} \text { for } 1 \text { bar, } \\
{ }^{\circ} \mathrm{C}\end{array}$} & \multirow{2}{*}{$\begin{array}{l}\mathrm{P} @ 25^{\circ} \mathrm{C} \text {, } \\
\text { bar }\end{array}$} & \multicolumn{2}{|c|}{ Energy density } \\
\hline & & & & & & & $\begin{array}{l}\text { Gravimetric, } \\
\mathrm{kJ} / \mathrm{kg}\end{array}$ & $\begin{array}{l}\text { Volumetric, } \\
\mathrm{kJ} / \mathrm{L}\end{array}$ \\
\hline \multirow[t]{3}{*}{ HT hydrides } & $\mathrm{Mg}$ & $7.6 *$ & 74.5 & 1.42 & 279 & 0.00001 & 2831.0 & 4020 \\
\hline & $\mathrm{Mg}_{2} \mathrm{Ni}$ & 3.3 & 64.5 & 2.75 & 255 & 0.0001 & 1064.3 & 2927 \\
\hline & $\mathrm{LaNi}_{4.25} \mathrm{Al}_{0.75}$ & 1.13 & 44.1 & 7.0 & 104 & 0.024 & 249.2 & 1744 \\
\hline \multirow[t]{6}{*}{ LT hydrides } & $75 \mathrm{~V}-5 \mathrm{Ti}-\mathrm{Cr}$ & $2.6 * *$ & 33 & 5.5 & -30 & 8 & 429.0 & 2360 \\
\hline & $\mathrm{TiV}_{0.62} \mathrm{Mn}_{1.5}$ & 2.15 & 28.6 & 5.45 & -6 & 3.8 & 307.5 & 1676 \\
\hline & $\mathrm{TiMn}_{2}$ HYDRALLOY & 1.9 & 27.4 & 6.0 & -28 & 11 & 260.3 & 1562 \\
\hline & TiMn $_{1.5}$ HYDMAC8 & 1.86 & 28.7 & 6.4 & -21 & 8.4 & 266.9 & 1708 \\
\hline & $\mathrm{LaNi}_{5}$ & 1.49 & 30.8 & 7.8 & 12 & 1.8 & 229.5 & 1790 \\
\hline & $\mathrm{LaNi}_{4.7} \mathrm{Sn}_{0.3}$ & 1.37 & 37 & 7.7 & 66 & 0.3 & 253.5 & 1952 \\
\hline
\end{tabular}

* For catalyzed $\mathrm{MgH}_{2}$, a hydrogen capacity > 6.0 wt.\% can be achieved.

** The V based alloys have theoretical H capacities over $3.5 \mathrm{wt} \%$, however, only partial of them can be used.

*** Data obtained from the Sandia Hydride Database. [18]

\section{List of figure captions:}

Fig. 1. Principle of the thermal battery based on metal hydrides.

Fig. 2. Selection of a working pair of hydride materials based on van't Hoff plot.

Fig. 3. (a) Schematic of the thermal battery prototype; (b) Hydride bed design of the prototype.

Fig. 4. Hydrogenation and dehydrogenation equilibrium pressure of $\mathrm{Mg} / \mathrm{MgH}_{2}$ and $\mathrm{TiMnV}$ hydride.

Fig. 5. Plots showing the (a) hydrogenation kinetics of the catalyzed $\mathrm{MgH}_{2}$, the (b) dehydrogenation kinetics of TiMnV hydride, (c) HT bed $\mathrm{H}_{2}$ charge test, and (d) LT bed $\mathrm{H}_{2}$ discharge test. 
Fig. 6. (a) Temperature profiles of HT-HBs and LT-HB during discharging (b) corresponding hydrogen flow rate, the pressure changes, (c) prototype performance of cooling and heating wattages. 


\section{Figures}

Figure1 grey

Discharging mode

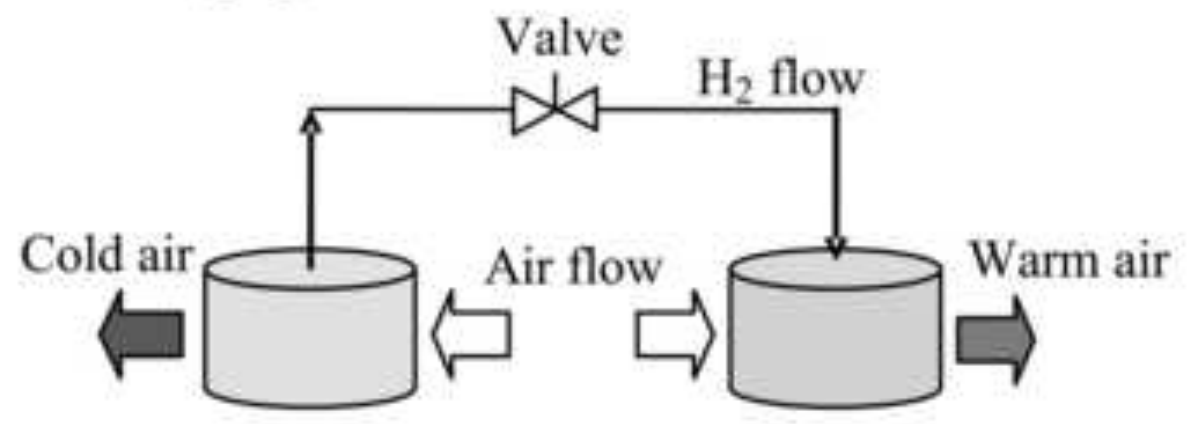

LT hydride bed

$\mathrm{M}_{2} \mathrm{H}+$ heat $\Rightarrow \mathrm{M}_{2}+\mathrm{H}_{2} \quad \mathrm{M}_{1}+\mathrm{H}_{2} \Rightarrow \mathrm{M}_{1} \mathrm{H}$ +heat
Recharging mode

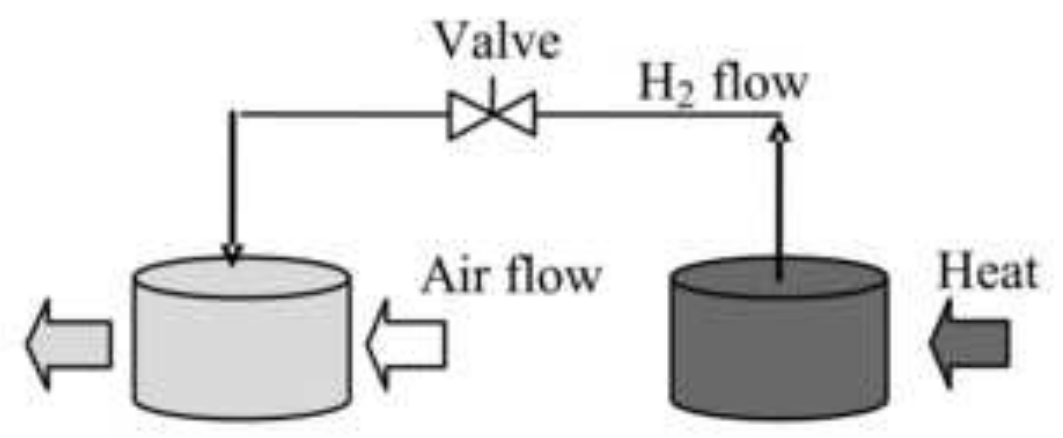

LT hydride bed $\quad$ HT hydride bed

$\mathrm{M}_{2}+\mathrm{H}_{2} \Rightarrow \mathrm{M}_{2} \mathrm{H}+$ heat $\mathrm{M}_{1} \mathrm{H}+$ heat $\Rightarrow \mathrm{M}_{1}+\mathrm{H}_{2}$ 
Temperature, ${ }^{\circ} \mathrm{C}$

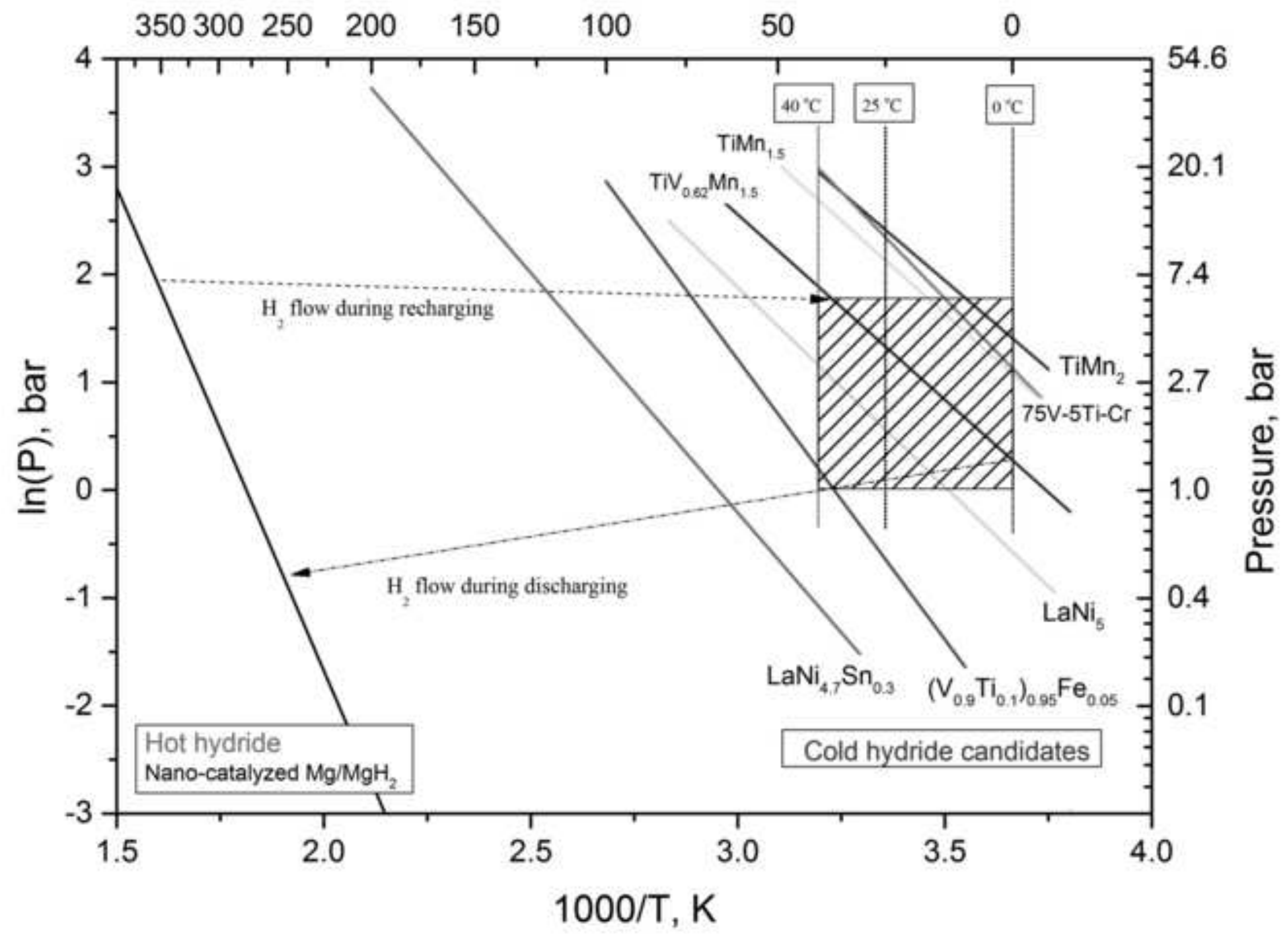




\section{(a)}
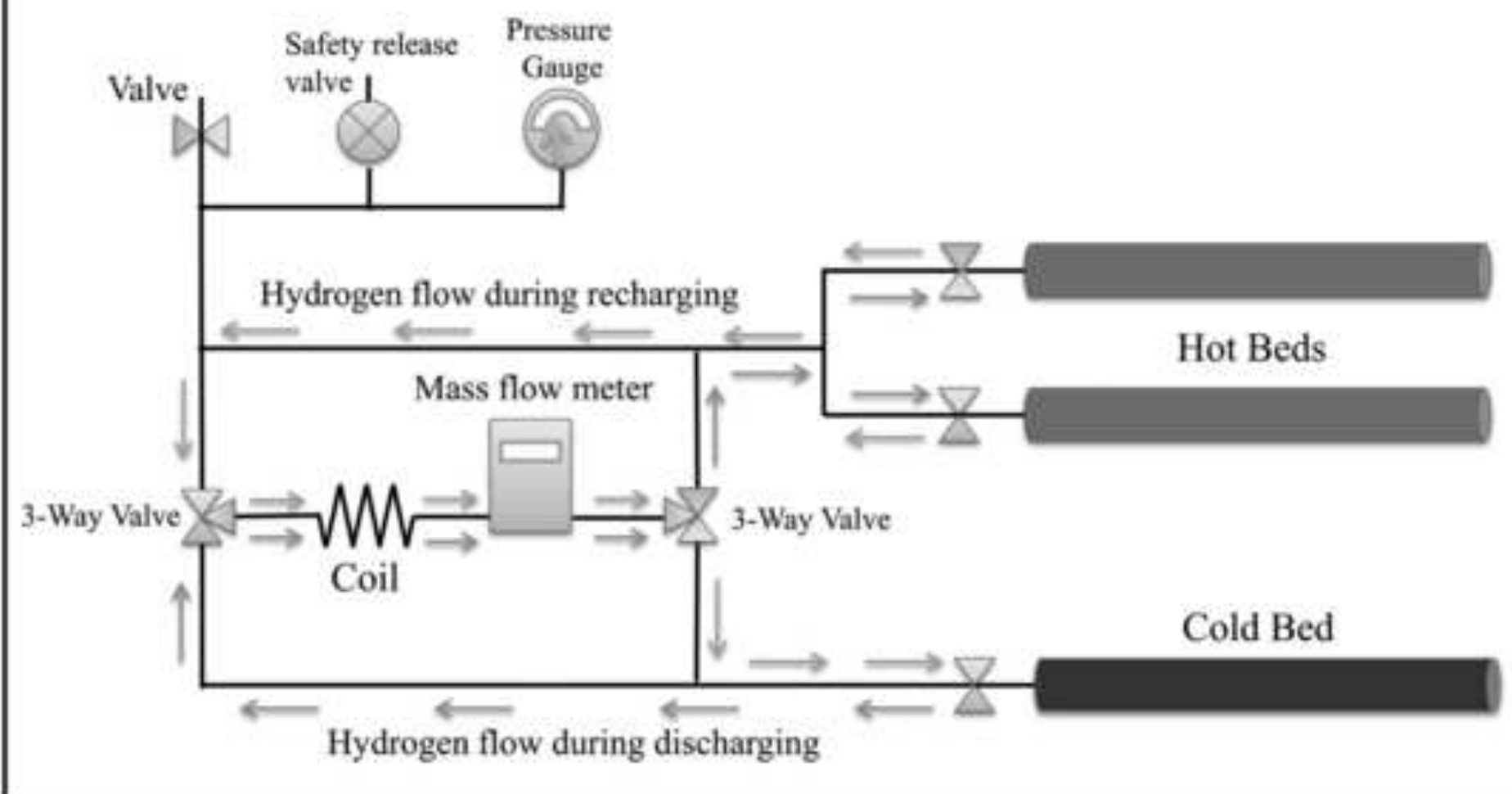

(b)

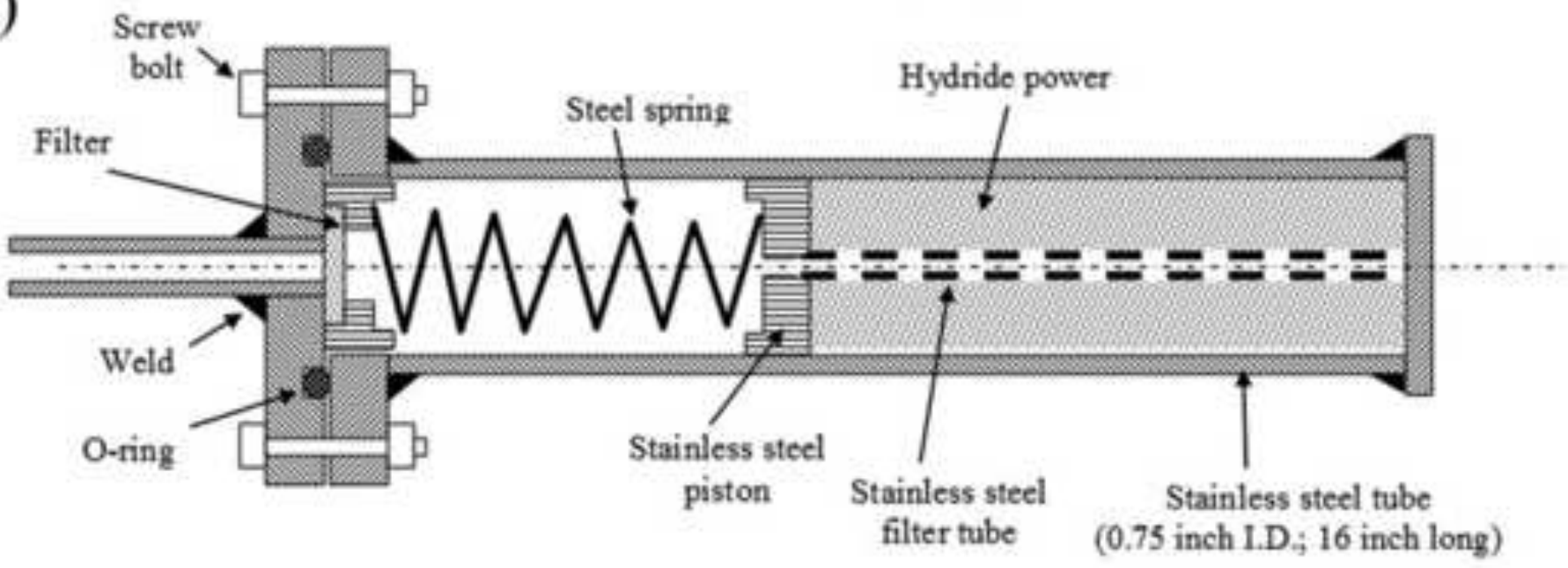


(a)

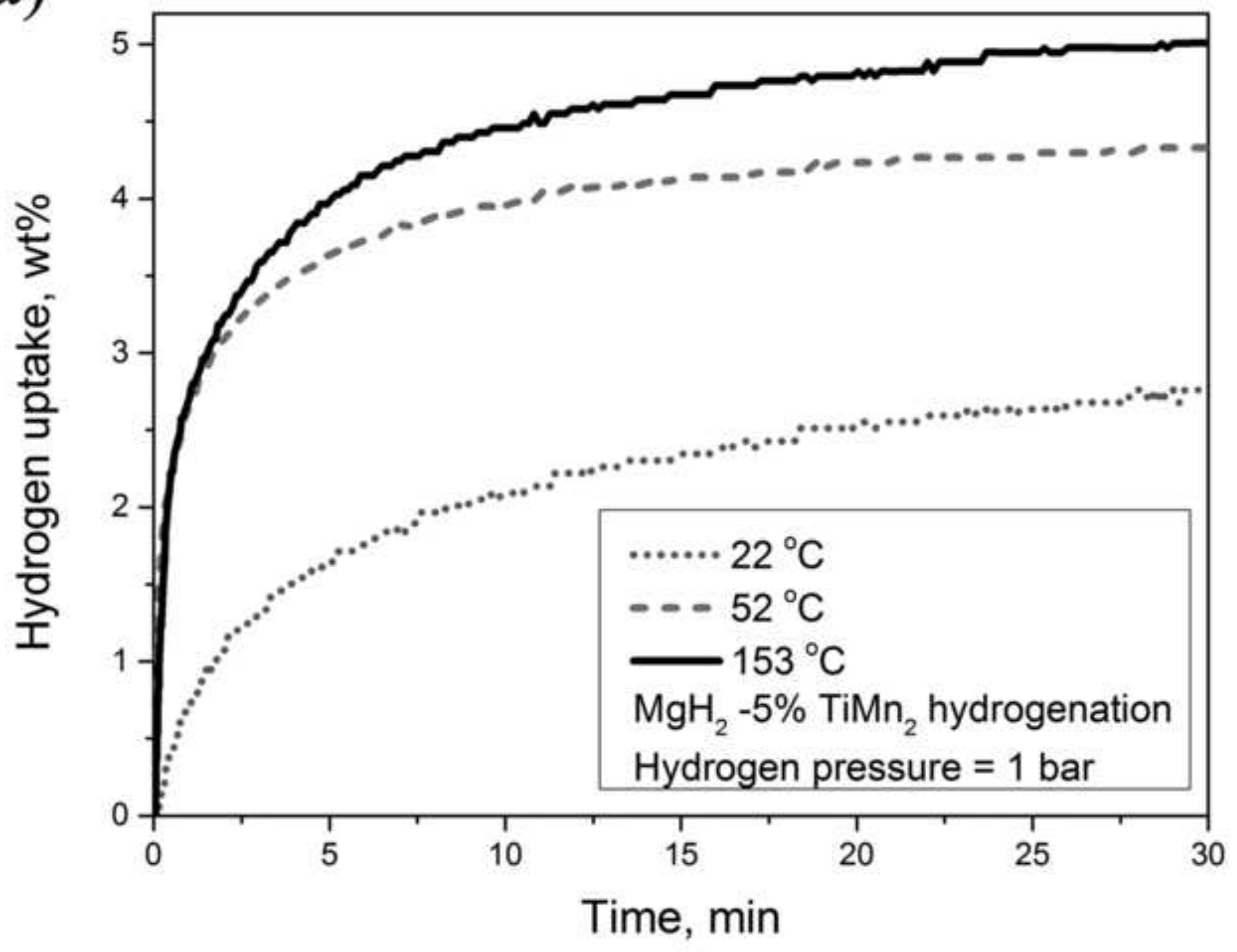


(b)

TiMnV hydride

Dehydrogenation at $25^{\circ} \mathrm{C}$

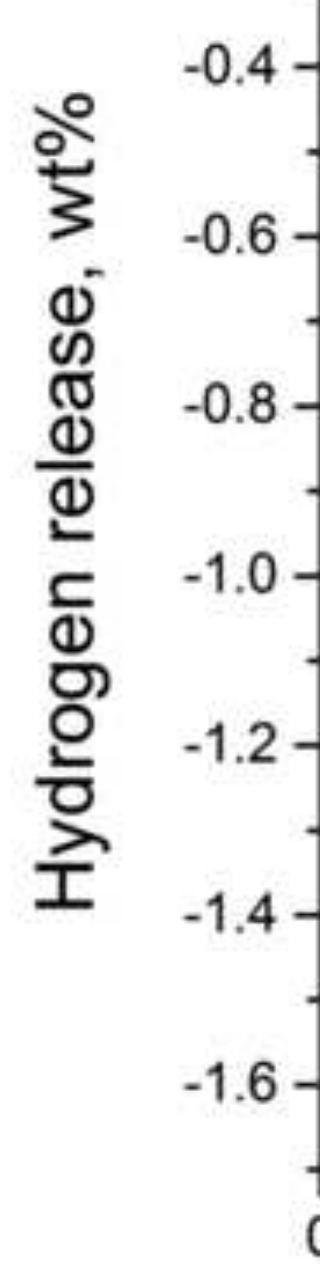

0

100

200

300

Time, sec 


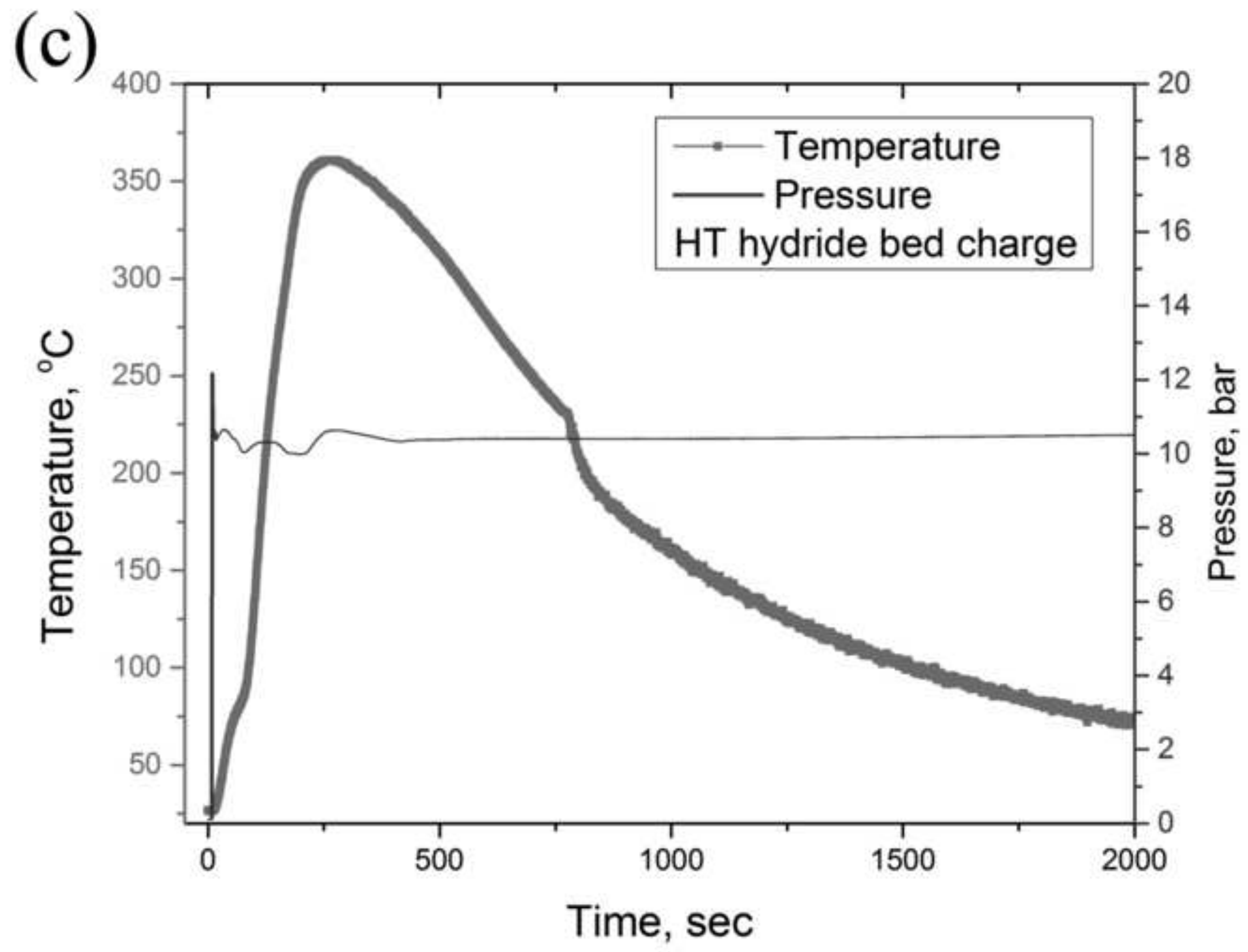


(d)

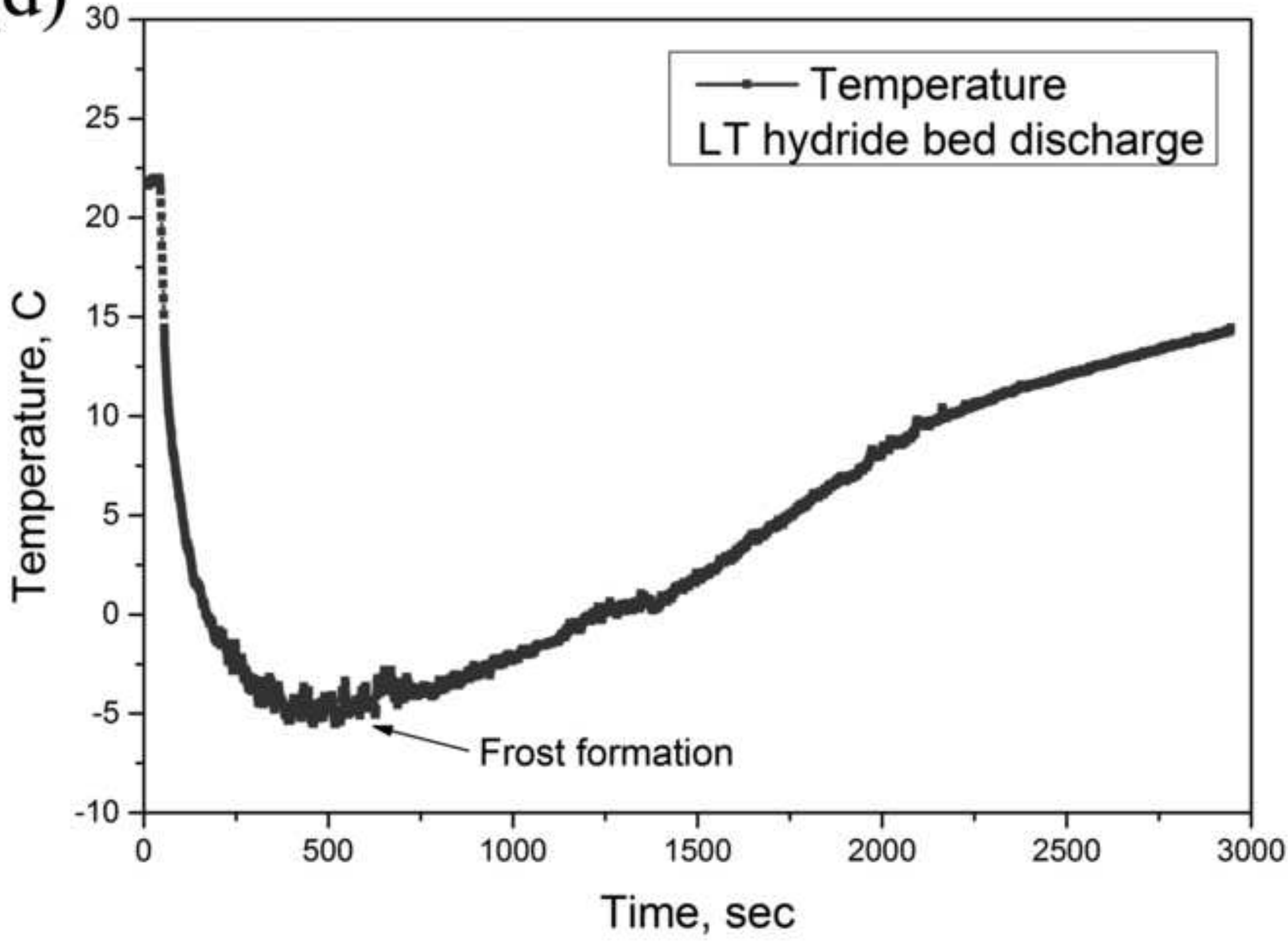

\section{LT hydride bed discharge}

Time, sec 
(a)

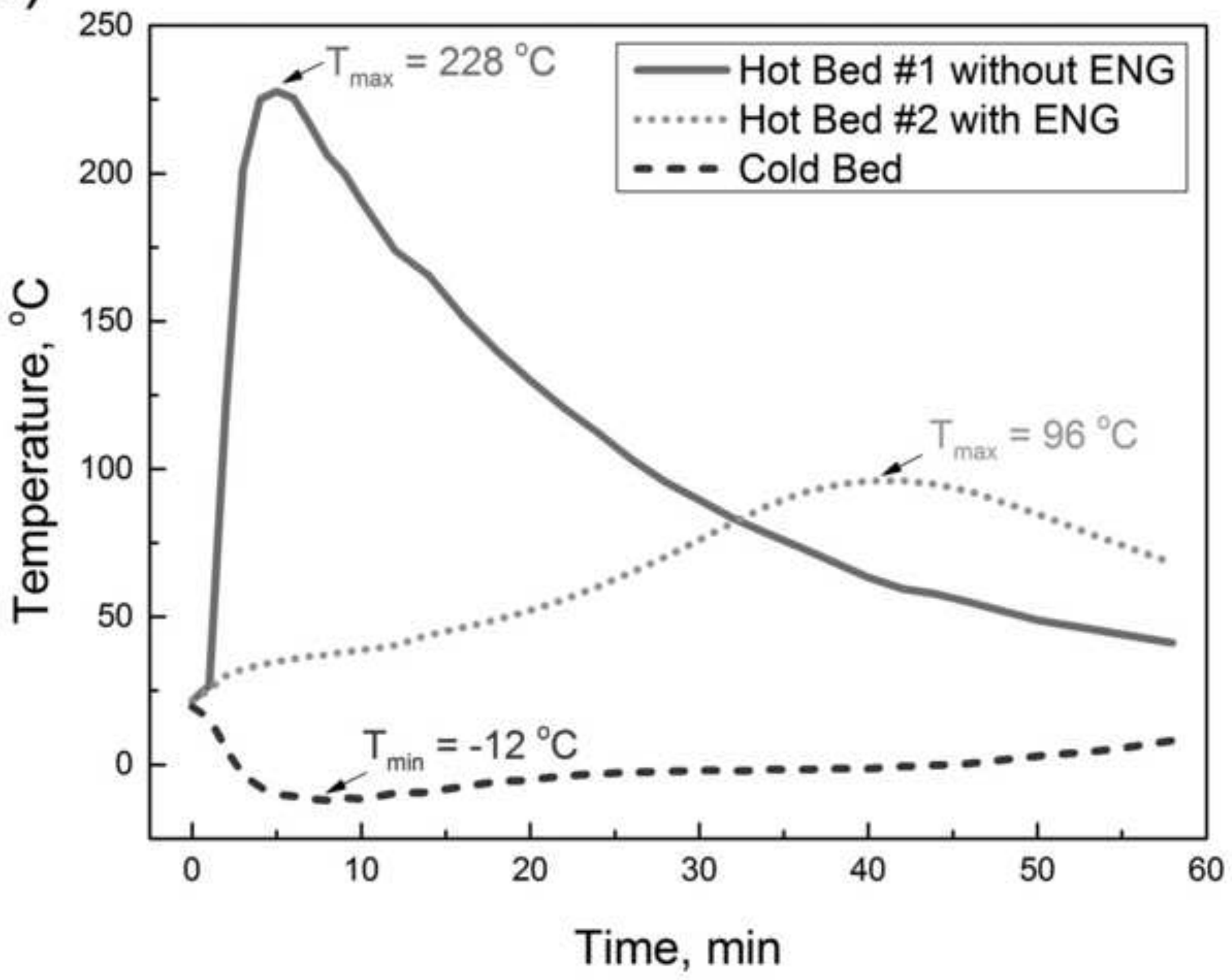


(b)

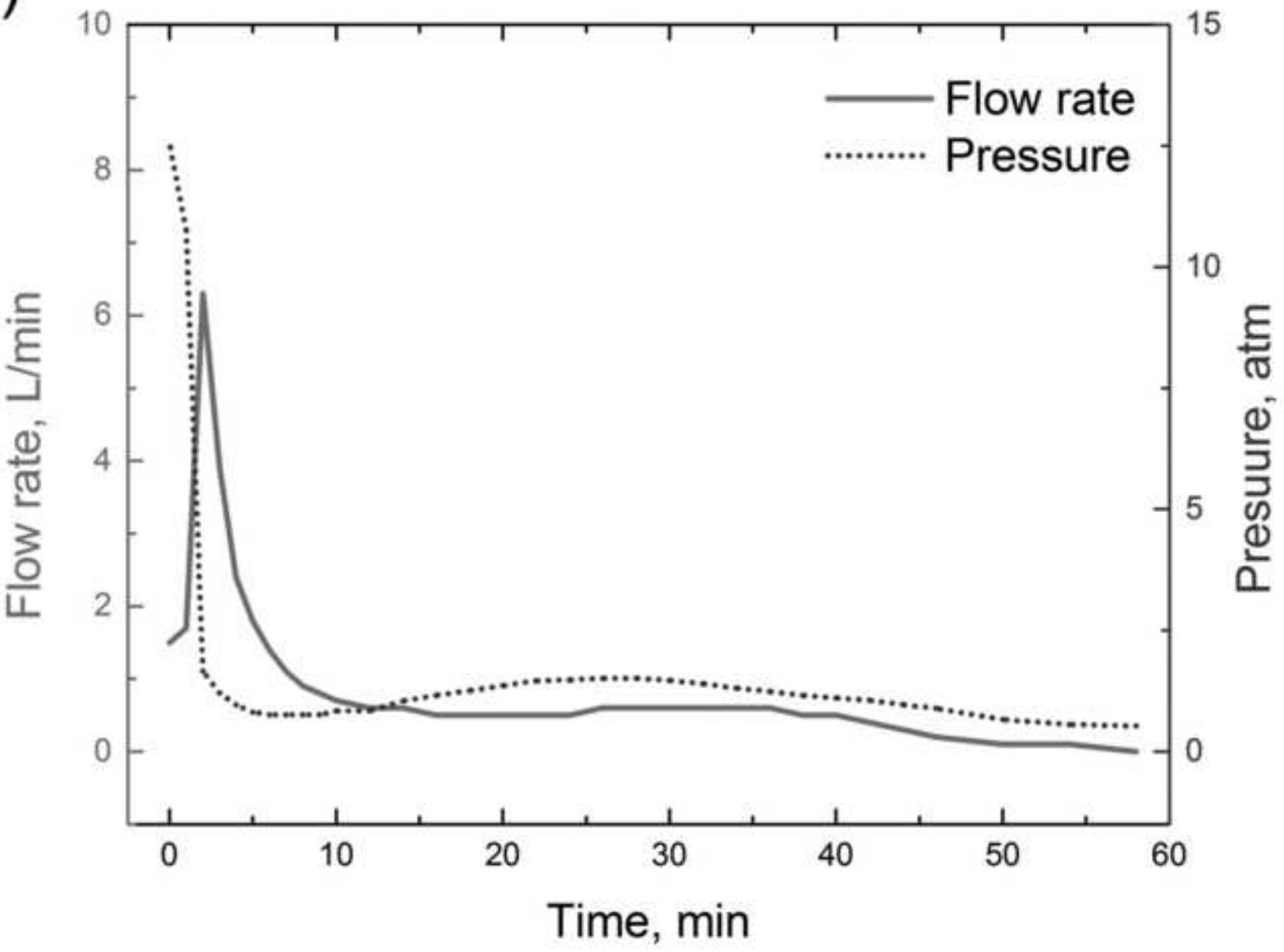




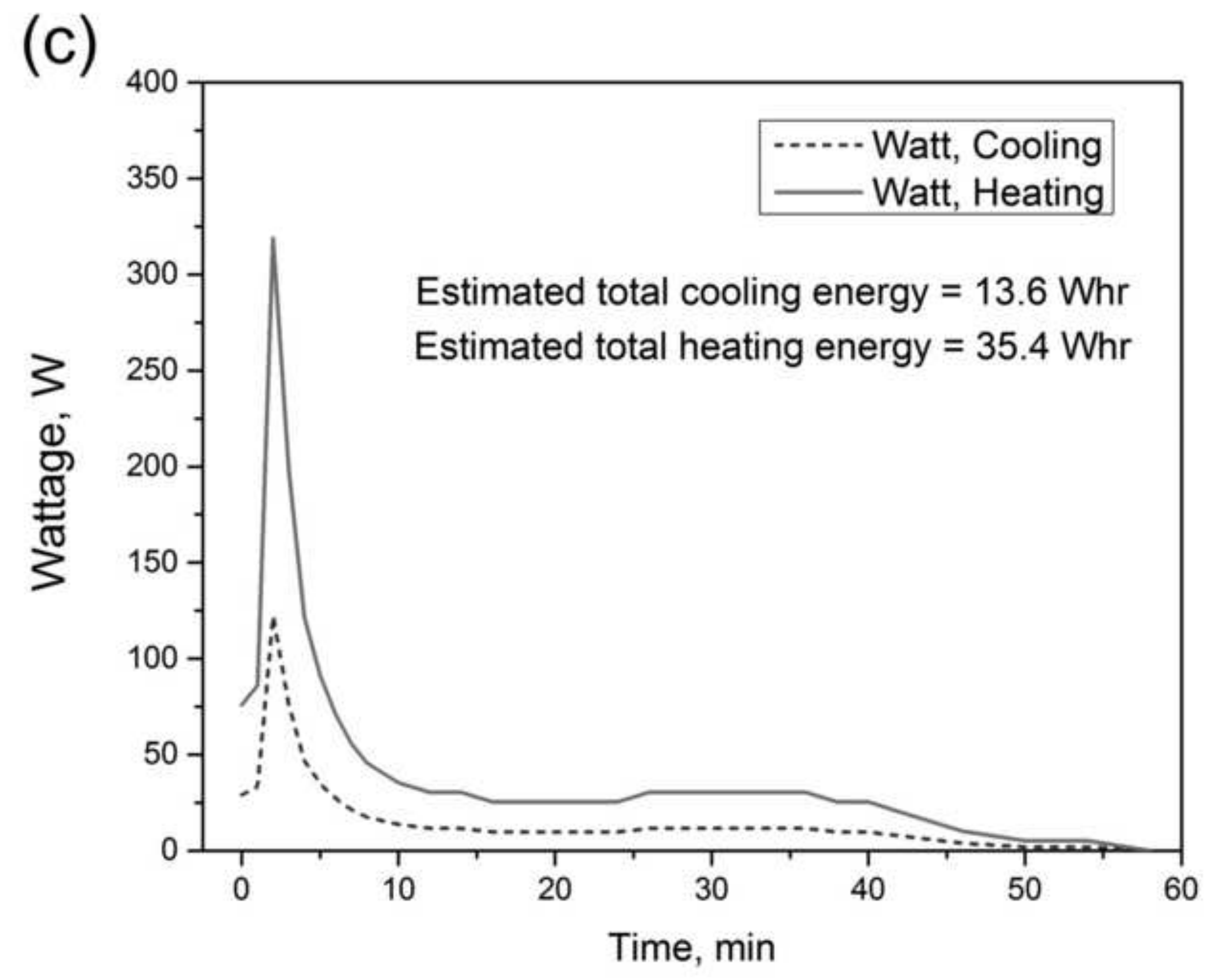

